\title{
A Mathematical Programming Model for Cell Formation Problem with Machine Replication
}

\author{
Reza Raminfar, ${ }^{1,2}$ Norzima Zulkifli, ${ }^{1}$ and Mohammadreza Vasilii \\ ${ }^{1}$ Department of Mechanical and Manufacturing Engineering, Universiti Putra Malaysia, Selangor, Malaysia \\ ${ }^{2}$ Department of Industrial Engineering, Lenjan Branch, Islamic Azad University, Esfahan, Iran
}

Correspondence should be addressed to Reza Raminfar; raminfar@iauln.ac.ir

Received 12 December 2012; Accepted 8 February 2013

Academic Editor: Ricardo Perera

Copyright (C) 2013 Reza Raminfar et al. This is an open access article distributed under the Creative Commons Attribution License, which permits unrestricted use, distribution, and reproduction in any medium, provided the original work is properly cited.

\begin{abstract}
Cell formation (CF) is a crucial aspect in the design of cellular manufacturing (CM) systems. This paper develops a comprehensive mathematical programming model for the cell formation problem, where product demands, cell size limits, sequence of operations, multiple units of identical machines, machine capacity, or machine cost are all considered. In this model, the intercell moves are restricted to be unidirectional from one cell to the downstream cells, without backtracking. The proposed model is investigated through several numerical examples. To evaluate the solution quality of the proposed model, it is compared with some well-known cell formation methods from the literature, by using group capability index (GCI) as a performance measure. The results and comparisons indicate that the proposed model produces solution with a higher performance.
\end{abstract}

\section{Introduction}

Group technology (GT) can be defined as a manufacturing philosophy aims at identifying similar parts and grouping them together to take advantage of their similarities in the manufacturing and design [1]. Cellular manufacturing (CM) is an application of GT which has emerged as a promising alternative manufacturing system [2]. It provides an environment to meet today's production requirements where manufacturing systems are often required to be reconfigured to respond to changes in product design and demand [3]. $\mathrm{CM}$ offers the advantages of simplified material flows, faster throughput, reduced setup times, reduced inventory, better control over the shop floor, and lower scrap rates [4].

The design and implementation of an effective CM system involves many issues such as, machine part cell formation (CF), production planning, layout design, and scheduling. The CF problem can be defined as "if the number, types, and capacities of production machines, the number and types of parts to be manufactured, and the routing plans and machine standards for each part are known, which machines and their associated parts should be grouped together to form cell?"
[5]. Numerous algorithms, heuristic and nonheuristic models have been developed in the literature, for solving the CF problem.

The CF problems can be classified into binary and comprehensive problems depending on whether or not processing times and the machine capacities are considered. The binary problem arises if the part demands are unknown when the CM system is being developed. Some examples of the binary problems can be found in Askin et al. [6], Chen and Cheng [7], and Chan and Milner [8]. If the part demand can be accurately predicted, processing time and machine capacities have to be included in the analysis. This gives rise to comprehensive problems [9]. Some examples of comprehensive models can be found in Logendran [10], Zolfaghari and Liang [11], Raminfar et al. [12], and Defersha and Chen [13].

The primary objective of this paper is to present a comprehensive model to solve the CF problem. The rest of this paper is organized as follows. Literature review and primary definitions of CF problem are addressed in Section 2. Detailed description of the problem and the proposed model are given in Section 3. Numerical examples are presented in 
TABLE 1: Machine-part matrix.

\begin{tabular}{llcccr}
\hline Machine types & \multicolumn{5}{c}{ Part type } \\
& 1 & 2 & 3 & 4 & 5 \\
\hline 1 & 1 & & 1 & 1 & \\
2 & & 1 & 1 & & 1 \\
3 & 1 & & 1 & & \\
4 & & 1 & & & 1 \\
\hline
\end{tabular}

Section 4 to illustrate the proposed model. Discussions to verify the model and conclusions are presented in Sections 5 and 6 , respectively.

\section{An Overview of Cell Formation (CF) Problem}

A variety of methods have been proposed by researchers for solving the CF problem. General overviews on the methods of solving the CF problem can be found in Singh [14], Selim et al. [1], and Papaioannou and Wilson [2]. These methods can be classified based on the procedures/formulations employed to form manufacturing cells and also the part families. Selim et al. [1] identified three solution strategies. The first class, which is referred to as part families identification (PFI), begins the cell formation process by identifying the families of parts first and then allocates machines to the families. The second class which is referred to as machine groups' identification (MGI) follows the reversal of the steps in the first class. Manufacturing cells (grouped machines) are first created based on similarity in part routings, and then the parts are allocated to cells. The third class which is referred to as part families/machine grouping (PF/MG) identifies the part families and machine groups simultaneously. As in the third class, the proposed model in this paper forms the part families and machine groups simultaneously.

The relationship between machines and part types is represented by machine part incidence matrix. The machine part incidence matrix has zero and one entries $\left(a_{i j}\right)$. A 1 entry in row $i$ and column $j ;\left(a_{i j}=1\right)$ of the matrix indicates that part $j$ has one or more operations on machine $i$, whereas a 0 entry indicates that it does not [3]. Each solution to a cell formation problem is displayed as a final part machine matrix in standard block diagonal form. In the block diagonal form matrix, out-of-cell operations are referred to as "exceptional elements," and the nonvisited machines are referred to as "voids". Table 1 presents an example of machine part incidence matrix. For instance, part type 1 has operations on machine types 1 and 3. Two cells (clusters) are formed as shown in Table 2. Cell 1 consists of machine types 2 and 4 and produces part types 5 and 2. Cell 2 consists of machine types 1 and 3 and produces part types 3, 1, and 4. Part type 3 needs to be processed on machine types 1 and 3 , in cell 2 . However, part type 3 also needs to be processed on machine type 2 which has been assigned to cell 1 . Part type 3 has an exceptional operation, so that it requires an intercell move. In Table 2, the 0 entry represents a void in cell 2 . A void indicates that a machine assigned to a cell is not required for the processing of
TABLE 2: Solution matrix of cell formation.

\begin{tabular}{llcccr}
\hline Machine types & \multicolumn{5}{c}{ Part type } \\
& 5 & 2 & 3 & 1 & 4 \\
\hline 2 & 1 & 1 & 1 & & \\
4 & 1 & 1 & & & \\
1 & & & 1 & 1 & 1 \\
3 & & & 1 & 1 & 0 \\
\hline
\end{tabular}

a particular part in that cell. In Table 2 it can be observed that part type 4 has no operation to be performed on the machine type 3 .

One way to increase the performance of any CF solution matrix is to minimize the number of exceptional elements. Obviously, this can be achieved by minimizing the number of intercell movements. For this purpose common solutions include replicating the bottleneck machines/facilities $[15,16]$, considering alternative process plans for part types [17, 18], and subcontracting the operations or part types $[13,19]$.

As mentioned earlier, numerous algorithms, heuristic and nonheuristic methods have been developed for the CF problem. However, most of these methods may be criticized due to their narrow scope and simplistic view of the problem. For instance, it is often neglected to consider the operations sequence of each part (i.e., the order in which the operations are performed on each part). An accurate count of intercell movements must be based on the number of cell visitations, and thus the need to include the sequence of operations into the analysis [20]. However, there is little analytical work that takes into account the operations sequence of the parts in evaluating the intercell movements.

From the literature it can be observed that several interrelated issues are involved in the cell formation problem, while most of the existing studies only discuss a fraction of these issues. Therefore, development of comprehensive cell formation methodology/procedures would seem to be necessary in order to simultaneously address these issues.

Consequently, in this research, a comprehensive mathematical model is proposed to solve CF problem. This mathematical programming model provides a large coverage of attributes such as part demand, intercell traffic movement cost with focusing on sequence of operations, different travel distances between cells, cell size limits, machine cost, machine capacity, and multiple identical machines. This model is also formulated in such a way as to ensure a unidirectional flow of material between cells.

In fact, it is widely accepted in the literature that the whole problem of designing a CMS, taking into accounts the numerous criteria involved, belongs to the class of NP-complete problems [21]. Furthermore, the additional features of the proposed model increase its complexity and combinatorial nature. For instance, one feature of the proposed model is to determine the number and types of machines to assign for each part type or cell; Logendran et al. [22] have shown that the problem involved with this feature is NP-hard. Therefore, the proposed mathematical model in this paper is NP-hard too, because of attributes model. 


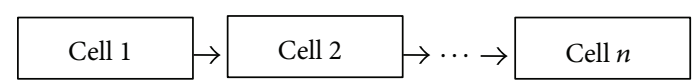

FIGURE 1: A Schematic view of the cells in the proposed plan [20].

\section{Mathematical Model Development}

3.1. Model Development. Consider a manufacturing system consisting of a number of machines to process different part types. Each part type may require some or all of the machines for processing. Demands for different part types are assumed to be known from work orders or from forecast. The proposed model of this study therefore determines how to form the manufacturing cells and how to group the part types into part families. This model is developed through considering multiple identical machines (machine replication), machines capacity, cell size limit, machines costs, and intercell movements costs. In order to cope with the possible cell revisitation and the resulting intercell backtracking traffic, a simple plan including certain positioning of the cells is considered. This plan divides the underlying manufacturing system into $n$ cells, as in Dahel [20]. In this regard, each cell is designed and positioned on the material flow pattern in such a way to achieve a unidirectional flow of intercell traffic. Figure 1 illustrates a schematic view of the cells in this plan, where the cells are numbered to reflect their relative position on the material flow pattern. For example, cell 2 follows cell 1 immediately, in turn cell 3 follows cell 2, and so on. However, in the case of existence of any exceptional part type in a cell, the exceptional part type(s) move to the cell immediately downstream for further processing. Accordingly, an operation $j$ of part $i$ may be assigned to, say, cell $l$ only if the preceding operation $(j-1)$ on the part's routing sequence is assigned either to cell $l$ or to any cell upstream of cell $l$. Since cell design is based on the operations sequence, exceptional parts (which should be processed in multiple cells) can process so without resorting to cell revisitation. This results in eliminating intercell backtracking and thus simplifies material handling. A general description of the proposed plan with flow line cells and its advantages over "job shop" cells can be found in Dahel [20].

In this paper, a mixed integer nonlinear programming model is developed to solve the above-mentioned problem. Notations including indices, coefficients, and parameters are described in the following section.

\subsection{Notations}

Indices

$i$ : Part type index: $i=1, \ldots, I$

$j$ : Index of operations of part type $i: j=1, \ldots, J_{i}$

l: Cell index: $l=1, \ldots, L$

$k$ : Machine index: $k=1, \ldots, K$.

\section{Coefficients and Parameters}

$D_{i}$ : Known demand of part type $i$

$M_{k}$ : Unit machine operating cost for machine type $k$

$F_{i[j k]}$ : Processing time of operation $j$ of part $i$ on machine type $k$

$C_{k}$ : Capacity of one machine of type $k$ for one time period

$R_{l l^{\prime}}$ : Cost of moving a unit of part type from cell $l$ to cell $l^{\prime}$

$L B_{l}$ : Minimum number of machines in cell $l$

$U B_{l}$ : Maximum number of machines in cell $l$.

Binary Decision Variables

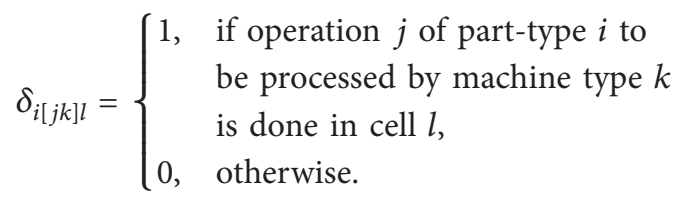

Subscripts $i[j k]$ of variable $\delta_{i[j k] l}$ indicate that machine $k$ is required to process operation $j$ of part type $i$. This information is known from the given part process plan.

\section{Integer Decision Variables}

$n_{k l}$ : Number of machine type $k$ assigned to cell $l$.

\subsection{Mathematical Formulation. Consider the following:}

$$
\begin{aligned}
\operatorname{minimize} Z= & \sum_{k=1}^{K} M_{k} \cdot \sum_{l=1}^{L} n_{k l} \\
& +\sum_{i=1}^{I} D_{i} \cdot \sum_{j=1}^{j_{i}-1} \sum_{k=1}^{K} \sum_{k^{\prime}=1}^{K} \sum_{l=1}^{L} \sum_{l^{\prime}=1}^{L} R_{l l^{\prime}} \delta_{i[j k] l} \cdot \delta_{i\left[(j+1) k^{\prime}\right] l^{\prime}}
\end{aligned}
$$

subject to

$$
\sum_{l=1}^{L} \delta_{i[j k] l}=1 ; \quad i=1, \ldots, I, j=1, \ldots, J_{i}, k=1, \ldots, K_{j i}
$$

$\sum_{i=1}^{I} \sum_{j=1}^{J_{i}} \delta_{i[j k] l} \geq n_{k l} ; \quad i=1, \ldots, I, j=1, \ldots J_{i}, k=1, \ldots, K$, $l=1, \ldots, L$, 


$$
\begin{gathered}
\sum_{i=1}^{I} \sum_{j=1}^{J_{i}} D_{i} . F_{i[j k]} \cdot \delta_{i[j k] l} \leq C_{k} \cdot n_{k l} ; \quad k=1, \ldots, K, l=1, \ldots, L \\
\delta_{i[j k] l} \leq \sum_{t=1}^{l} \delta_{i[(j-1) k] t}, \quad i=1, \ldots, I, \quad j=2, \ldots J_{i} \\
\quad k=1, \ldots, K, l=1, \ldots, L \\
L B_{l} \leq \sum_{k=1}^{K} n_{k l} \leq U B_{l} ; \quad l=1, \ldots, L \\
n_{k l} \geq 0 \text { and integer, } \quad \delta_{i[j k] l}=0,1, \quad \forall i, j, l, l^{\prime}, k, k^{\prime}
\end{gathered}
$$

The objective function of the proposed model is given by (2). The objective function is the sum of machine cost and intercell material handling cost. The first term of the objective function is the machine operating cost. It is assumed that the machines can be included when they are needed and can be removed from the system when they are not required. The second term of the objective function is the intercell material handling cost. This cost function is nonlinear, since it has been assumed that the distances between each pair of cells are different (part type $i$ after completion of its operation $j$ by machine $k$ in cell $l$, moves to machine $k^{\prime}$ for the next operation, $j+1$, in cell $l^{\prime}$ ). It is further assumed that the specifications of different part types (for example, size or volume of different part types) do not influence the material handling cost.

Constraints of the model consist of (3) to (8). Constraint set (3) assigns each part's operation to exactly one cell. Constraint set (4) ensures that, once machine $k$ is assigned to cell $l$, then the operations of part types may be assigned to that machine. Constraint set (5) ensures that sufficient machine capacity is assigned to each cell. Furthermore, it determines the number of machine types which will be required. Constraint set (6) states that an operation $j$ of part type $i$ by machine type $k$ may be performed in cell $l$, only if the preceding operation $(l-1)$ is performed either in cell $l$ or in any cell upstream of cell $l$. Constraint sets (7) specifies the minimum number $(L B)$ and the maximum number $(U B)$ of machines in cell $l$. Constraint sets (8) impose nonnegativity and integrality. The model, as shown previously, has been adapted and modified from Atmani et al. [23], Dahel [20], and Chen [24].

3.4. Linearization of the Proposed Model. The objective function in the model is a nonlinear function due to its second term for material handling cost. This term can be linearized using a procedure as follows. First, consider the second term of the objective function as follows:

$$
\sum_{i=1}^{I} D_{i} \cdot \sum_{j=1}^{j_{i}-1} \sum_{k=1}^{K} \sum_{k^{\prime}=1}^{K} \sum_{l=1}^{L} \sum_{l^{\prime}=1}^{L} R_{l l^{\prime}} \delta_{i[j k] l} \cdot \delta_{i\left[(j+1) k^{\prime}\right] l^{\prime}}
$$

It can be modified as follows:

$$
\sum_{i=1}^{I} \sum_{j=1}^{J_{i}} \sum_{k=1}^{K} \sum_{k^{\prime}=1}^{K} \sum_{l=1}^{L} \sum_{L^{\prime}=1}^{L} R_{l l^{\prime}} \cdot\left[\delta_{i[j k] l} \cdot \delta_{i\left[(j+1) k^{\prime}\right] l^{\prime}}\right] .
$$

In order to linearize the previous expression, that assume

$$
Y_{i[j k] l k^{\prime} l^{\prime}}=\delta_{i[j k] l} \cdot \delta_{i\left[(j+1) k^{\prime}\right] l^{\prime}} .
$$

These variables imply that

$$
Y_{i[j k] l k^{\prime} l^{\prime}}= \begin{cases}1, & \text { if part type } i \text { moves to machine } k^{\prime} \\ & \text { in cell } l^{\prime} \text { to perform operation } \\ & (j+1) \text { after performing operation } j \\ & \text { on machine } k \text { in cell } l, \\ 0, & \text { otherwise. }\end{cases}
$$

Finally, the second term of objective function can be replaced by the following linear expression:

$$
\sum_{i=1}^{I} \sum_{j=1}^{J_{i}-1} \sum_{k=1}^{K} \sum_{k^{\prime}=1}^{K} \sum_{l=1}^{L} \sum_{L^{\prime}=1}^{L} R_{l l^{\prime}} Y_{i[j k] l k^{\prime} l^{\prime}}
$$

Moreover, the following constraints should be added to this model:

$$
\begin{aligned}
& \delta_{i[j k] l}+\delta_{i\left[(j+1) k^{\prime}\right] l^{\prime}}-2 Y_{i[j k] l k^{\prime} l^{\prime}} \geq 0, \\
& \delta_{i[j k] l}+\delta_{i\left[(j+1) k^{\prime}\right] l^{\prime}}-Y_{i[j k] l k^{\prime} l^{\prime}} \leq 1,
\end{aligned}
$$

Constraints sets (14) and (15) imply that $Y_{i[j k] l k^{\prime} l^{\prime}}(t)$ is equal to 1 , if one unit of part type $i$ is moved to machine $k^{\prime}$ in cell $l^{\prime}$ for operation $(j+1)$ after performing operation $j$ on machine $k$ in cell $l$.

\section{Numerical Examples}

Two numerical examples with different structures from existing literature are presented in this section. The examples have been solved using LINGO 12.0, a commercially available optimization software, on a personal computer with Intel Core2 Duo T6400@2.00 GHz processor and 4 GB RAM.

Example 1. Data set of this example has been adapted from Dahel [20] with slight modifications. In this example, 11 part types and 7 machine types are considered. A three-cell partition is sought, and the minimum number of machines allowed per cell is set to two and four, respectively. Detailed production demand for each part type, machine operating costs, and machine capacity for each machine type are presented in Table 3. Meanwhile, Table 4 represents partmachine requirements, sequence of operations for each part type, and processing time needed for each operation. From Table 4 it can be observed that, for example, part type 4 requires three operations with the first operation on machine 6 , the second on machine 3 , and the third on machine 4 . In Table 4, the lower number in each cell represents the processing time requirement corresponding to its relative operation. 
TABle 3: Machine cost, machine capacity, and part processing demand for Example 1.

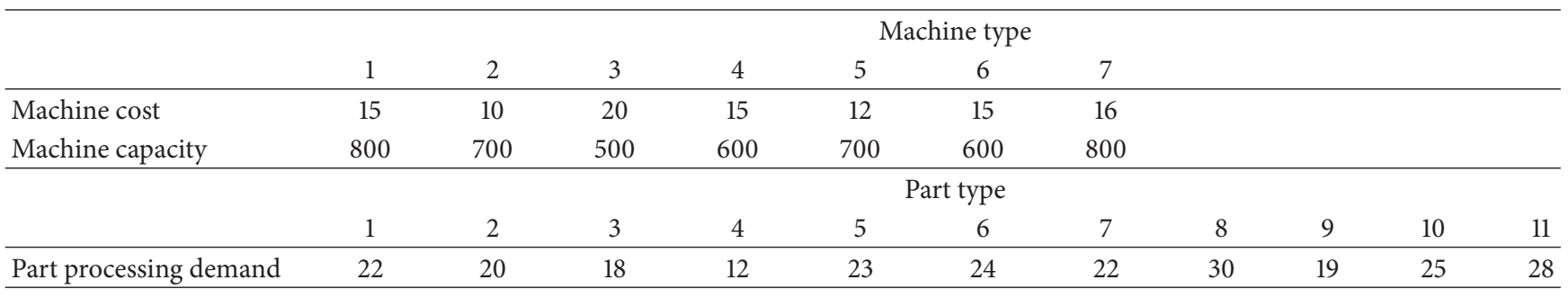

TABle 4: Partial input data for Example 1.

\begin{tabular}{|c|c|c|c|c|c|c|c|c|c|c|c|}
\hline & \multicolumn{11}{|c|}{ Part type } \\
\hline & 1 & 2 & 3 & 4 & 5 & 6 & 7 & 8 & 9 & 10 & 11 \\
\hline $\begin{array}{l}\text { Machine } \\
\text { number }\end{array}$ & \multicolumn{11}{|c|}{ Part operation requirement (upper number) and processing time requirement (lower number) } \\
\hline \multirow{2}{*}{1} & 2 & & 1 & & & & 2 & & & & 1 \\
\hline & 10.9 & & 8.9 & & & & 21.8 & & & & 20 \\
\hline \multirow{2}{*}{2} & 1 & 1 & & & & 2 & & & 2 & & \\
\hline & 12.7 & 21.0 & & & & 14.6 & & & 11.1 & & \\
\hline \multirow{2}{*}{3} & & 2 & & 2 & & 1 & & & 1 & & 2 \\
\hline & & 12.5 & & 12.5 & & 20.0 & & & 18.4 & & 7.1 \\
\hline \multirow{2}{*}{4} & & & & 3 & 2 & & & 2 & & 2 & \\
\hline & & & & 10.0 & 7.8 & & & 4.0 & & 4.8 & \\
\hline \multirow{2}{*}{5} & & & 2 & & & & 1 & & & & \\
\hline & & & 11.7 & & & & 19.1 & & & & \\
\hline \multirow{2}{*}{6} & & & 3 & 1 & & & & & & & 3 \\
\hline & & & 13.3 & 5.0 & & & & & & & 6.4 \\
\hline \multirow{2}{*}{7} & & & & & 1 & & & 1 & & 1 & \\
\hline & & & & & 27.8 & & & 8.0 & & 12.8 & \\
\hline
\end{tabular}

TABLE 5: Intercell material handling cost for Example 1.

\begin{tabular}{lccc}
\hline Cell No. & 1 & 2 & 3 \\
\hline 1 & 0.0 & 1.0 & 1.4 \\
2 & 1.0 & 0.0 & 1.2 \\
3 & 1.4 & 1.2 & 0.0 \\
\hline
\end{tabular}

For instance, 5 time units of processing on machine type 6 are required in order to produce one unit of part type 4 . In other words, part type 4 requires 5 time units of the capacity of machine type 6 . In addition, the intercell material handling costs are shown in Table 5.

Considering the part-operation requirements in Table 4, in order to reduce the number of variables and constraints, the variables which can be fixed to zero were removed from the model using sparse set membership filtering technique of LINGO [25]. After fixing these variables, some constraints became redundant and were subsequently removed. The LINGO solver defined this model as mixed integer linear program (MILP) and used the branch and bound (B-andB) method to solve it. This problem consists of 222 variables (including 96 integer variables) and 284 constraints. The global optimal solution was achieved after 13 seconds of the solver running, and the objective value (i.e., the total cost) of the problem was 282.8. Table 6 presents a solution matrix for this example, where bracketed numbers show the number of corresponding machine assigned to each cell.

This solution has four exceptional part type, including parts $4,6,9$, and 11. For instance, part type 4 performs its first two operations in cell 2 and then moves downstream to cell 3, for its third operation. Accordingly, intercell traffic follows a unidirectional pattern from cell 2 toward cell 3 , and no backtracking is happened.

From Table 6 it can be observed that multiple units of the same machine can be used in different cells or even in each cell. For instance, two machines of type 3 have been assigned to cell 1 , since the capacity provided by a single machine for these two machine types is not sufficient to satisfy the capacity requirements of the parts assigned to this cell. Similarly two 
TABLE 6: A solution matrix for Example 1.

\begin{tabular}{|c|c|c|c|c|c|c|c|c|c|c|c|c|}
\hline \multirow{2}{*}{ Cell number } & \multirow{2}{*}{ Machine number } & \multicolumn{11}{|c|}{ Part type } \\
\hline & & 1 & 2 & 6 & 11 & 3 & 4 & 7 & 9 & 5 & 8 & 10 \\
\hline \multirow{3}{*}{1} & 1 & 2 & & & 1 & & & & & & & \\
\hline & 2 & 1 & 1 & & & & & & & & & \\
\hline & $3[2]$ & & 2 & 1 & 2 & & & & & & & \\
\hline \multirow{4}{*}{2} & 1 & & & & & 1 & & 2 & & & & \\
\hline & 3 & & & & & & 2 & & 1 & & & \\
\hline & 5 & & & & & 2 & & 1 & & & & \\
\hline & 6 & & & & 3 & 3 & 1 & & & & & \\
\hline \multirow{3}{*}{3} & 2 & & & 2 & & & & & 2 & & & \\
\hline & 4 & & & & & & 3 & & & 2 & 2 & 2 \\
\hline & $7[2]$ & & & & & & & & & 1 & 1 & 1 \\
\hline
\end{tabular}

TABLE 7: Machine cost, machine capacity, and part processing demand for Example 2.

\begin{tabular}{|c|c|c|c|c|c|c|c|c|c|c|}
\hline & \multicolumn{10}{|c|}{ Machine type } \\
\hline & 1 & 2 & 3 & 4 & 5 & 6 & 7 & 8 & & \\
\hline Machine cost & 70 & 160 & 160 & 180 & 165 & 65 & 110 & 185 & & \\
\hline \multirow[t]{3}{*}{ Machine capacity } & 18000 & 18000 & 20000 & 20000 & 22000 & 18400 & 18000 & 20000 & & \\
\hline & \multicolumn{10}{|c|}{ Part type } \\
\hline & 1 & 2 & 3 & 4 & 5 & 6 & 7 & 8 & 9 & 10 \\
\hline \multirow[t]{3}{*}{ Part processing demand } & 50 & 150 & 500 & 75 & 500 & 1200 & 1500 & 750 & 5000 & 1300 \\
\hline & \multicolumn{10}{|c|}{ Part type (continued) } \\
\hline & 11 & 12 & 13 & 14 & 15 & 16 & 17 & 18 & 19 & 20 \\
\hline Part processing demand & 1239 & 575 & 1239 & 1500 & 14000 & 39 & 900 & 339 & 390 & 304 \\
\hline
\end{tabular}

machines of type 7 are included in cell 3, and two machines of type 1 are assigned to cells 1 and 2 . Two machines types of 2 are assigned to cells 1 and 3 too.

Example 2. In this example, the data for part-machine incidence matrix have been adapted from Chandrasekharan and Rajagopalan [26]. 3 cells, 20 part types, and 8 machine types are considered in this example. The minimum and maximum numbers of machines in each cell are 2 and 5, respectively. Machine cost and machine capacity for each machine type and detailed production demands for each part type are presented in Table 7 . Part-machine requirements and processing time needed for each operation are shown in Table 8 . For example, the 3rd column of Table 8 shows that there are 2 operations for processing part 2. It also indicates that machines 1 and 3 are required to perform operations 1 to 2 , respectively, for part type 1 . Furthermore, the intercell material handling costs are considered to be the same as those in the first example.

The LINGO code of this example was written similar to that of the first example. The LINGO solver detected this example as a mixed integer linear program (MILP) and used the branch and bound (B-and-B) method to solve it. The linear model of this example consists of 576 variables (including 207 integer variables) and 731 constraints. The solution was achieved after 2 minutes and 44 seconds of the solver running. The total cost of this problem (which appears as objective value in the LINGO solution report) was 4612.8 . Table 9 shows the solution matrix (machines and part types groups) for this example. Recall that the bracketed numbers show the number of corresponding machine assigned to each cell.

It is observed that in this solution there are four exceptional part types (including parts 3,11, 18, and 20) with 12 exceptional elements. Through a careful consideration of all the factors mentioned before, it can be seen that the constraints (5) and (7) have significant influence on the solution and the solver runtime. For instance, if the maximum number of machines in each cell is increased from 5 to 6 , the solver runtime will be reduced by $54 \%$ through generating second remarkable results, where there is no exceptional part type in the solution (Table 10).

\section{Discussion}

This section discusses about conditions and advantages of the proposed mathematical model. The performance of the proposed model is compared with those of some existing well-known methodologies.

As matter of fact, it seems that the proposed model has some advantages over other research models. For instance, Askin et al. [6], Chan and Milner [8] are solved CF model by binary models and they do not consider substantial attributes 
TABle 8: Partial input data for Example 2.

\begin{tabular}{|c|c|c|c|c|c|c|c|c|c|c|c|c|c|c|c|c|c|c|c|c|}
\hline & \multicolumn{20}{|c|}{ Part type } \\
\hline & 1 & 2 & 3 & 4 & 5 & 6 & 7 & 8 & 9 & 10 & 11 & 12 & 13 & 14 & 15 & 16 & 17 & 18 & 19 & 20 \\
\hline $\begin{array}{l}\text { Machine } \\
\text { number }\end{array}$ & \multicolumn{20}{|c|}{ Part operation requirement (upper number) and processing time requirement (lower number) } \\
\hline \multirow{2}{*}{1} & & 1 & 1 & & & & & 1 & 1 & & 1 & & 1 & 1 & & 1 & 1 & & 1 & \\
\hline & & 0.55 & 3.59 & & & & & 2.4 & 0.4 & & 3 & & 0.4 & 1.8 & & 1.24 & 1 & & 3.5 & \\
\hline \multirow{2}{*}{2} & & & 2 & 2 & & 1 & 1 & & & & & & & 2 & & & & 1 & & 1 \\
\hline & & & 2.84 & 0.59 & & 3.83 & 2.03 & & & & & & & 3.7 & & & & 0.5 & & 2.4 \\
\hline \multirow{2}{*}{3} & & 2 & & & & & & 2 & 2 & & 2 & & 2 & 3 & & 2 & 3 & & 2 & \\
\hline & & 2.01 & & & & & & 1.8 & 0.9 & & 0.6 & & 3.5 & 2.6 & & 3.8 & 1.5 & & 2 & \\
\hline \multirow{2}{*}{4} & & & 3 & 1 & & 3 & 2 & & & 2 & & & & & & & & 2 & & 2 \\
\hline & & & 2.01 & 2.8 & & 0.32 & 3.52 & & & 2.4 & & & & & & & & 0.6 & & 0.8 \\
\hline \multirow{2}{*}{5} & 1 & & & & 2 & 2 & & & & 1 & & 1 & & & 1 & & 2 & & & \\
\hline & 3.34 & & & & 3.96 & 0.85 & & & & 2.9 & & 0.4 & & & 1.2 & & 0.3 & & & \\
\hline \multirow{2}{*}{6} & 2 & & & & 1 & & & & 3 & 3 & & 3 & & & 2 & & & & & 3 \\
\hline & 2.18 & & & & 1.78 & & & & 0.4 & 1 & & 0.2 & & & 1.7 & & & & & 0.3 \\
\hline \multirow{2}{*}{7} & & & 4 & 3 & & 4 & 4 & & & & 3 & 2 & & & & & & 3 & & 5 \\
\hline & & & 1.13 & 1.8 & & 1.31 & 2.6 & & & & 1.5 & 3.5 & & & & & & 3.9 & & 2.5 \\
\hline \multirow{2}{*}{8} & & & 5 & 4 & & 5 & 3 & & & & & & & & & & & 4 & & 4 \\
\hline & & & 2.17 & 0.16 & & 0.3 & 0.3 & & & & & & & & & & & 0.6 & & 1.4 \\
\hline
\end{tabular}

TABle 9: A solution matrix for Example 2.

\begin{tabular}{|c|c|c|c|c|c|c|c|c|c|c|c|c|c|c|c|c|c|c|c|c|c|}
\hline \multirow{2}{*}{ Cell number } & \multirow{2}{*}{ Machine number } & \multicolumn{20}{|c|}{ Part type } \\
\hline & & 1 & 2 & 3 & 5 & 8 & 9 & 11 & 13 & 14 & 16 & 17 & 18 & 19 & 20 & 10 & 12 & 15 & 4 & 6 & 7 \\
\hline \multirow{5}{*}{1} & 1 & & 1 & 1 & & 1 & 1 & 1 & 1 & 1 & 1 & 1 & & 1 & & & & & & & \\
\hline & 2 & & & & & & & & & 2 & & & 1 & & 1 & & & & & & \\
\hline & 3 & & 2 & & & 2 & 2 & 2 & 2 & 3 & 2 & 3 & & 2 & & & & & & & \\
\hline & 5 & 1 & & & 2 & & & & & & & 2 & & & & & & & & & \\
\hline & 6 & 2 & & & 1 & & 3 & & & & & & & & & & & & & & \\
\hline \multirow{4}{*}{2} & 4 & & & & & & & & & & & & & & 2 & 2 & & & & & \\
\hline & 5 & & & & & & & & & & & & & & & 1 & 1 & 1 & & & \\
\hline & $6[2]$ & & & & & & & & & & & & & & 3 & 3 & 3 & 2 & & & \\
\hline & 7 & & & & & & & 3 & & & & & & & & & 2 & & & & \\
\hline \multirow{5}{*}{3} & 2 & & & 2 & & & & & & & & & & & & & & & 2 & 1 & 1 \\
\hline & 4 & & & 3 & & & & & & & & & 2 & & & & & & 1 & 3 & 2 \\
\hline & 5 & & & & & & & & & & & & & & & & & & & 2 & \\
\hline & 7 & & & 4 & & & & & & & & & 3 & & 5 & & & & 3 & 4 & 4 \\
\hline & 8 & & & 5 & & & & & & & & & 4 & & 4 & & & & 4 & 5 & 3 \\
\hline
\end{tabular}

such as demand, time, or cost, but the proposed model is covered many attributes. Other examples such as, Defersha and Chen [27], and Zolfaghari and Liang [11] are comprehensive models to solve CF problem and consider many attributes such as considering multiple copies of identical machine; nevertheless in these models part type flow between cells is not unidirectional but the proposed model has this attribute; or the proposed mixed integer linear programming model is solved by branch and bound algorithm which can be found global optimal solution, but the previous two researches models are found local optimum solution.

On the other hand, based on the examination of the literature, in order to quantify the performance of the different methodologies/solutions, "performance measures" are used. For this purpose, several different performance measures have been suggested in the literature. A comprehensive review of various performance measures of CF solutions was presented by Sarker [28]. Through various performance 
TABLE 10: A secondary solution for Example 2, after applying a new limit for maximum number machines in each cell.

\begin{tabular}{lcc}
\hline Cell number & Machine number & Part number \\
\hline 1 & $2,4,5,6,7,8$ & $1,5,6,7,10,12,20$ \\
2 & $1,3,5,6[2]^{*}$ & $9,13,15,17$ \\
3 & $1,2,3,4,7,8$ & $2,3,4,8,11,14,16,18,19$ \\
\hline
\end{tabular}

${ }^{*}$ Bracketed numbers show the number of corresponding machine assigned to each cell.

TABLE 11: CF results of the proposed model versus the results of other methods.

\begin{tabular}{llccc}
\hline Example number & Model & $e_{o}$ & $e$ & GCI \\
\hline \multirow{2}{*}{1} & ROC & 5 & 25 & $80 \%$ \\
& Proposed model & 4 & 25 & $84 \%$ \\
\hline \multirow{2}{*}{2} & ROC2 & 15 & 61 & $75.4 \%$ \\
& HPH & 9 & 61 & $85.2 \%$ \\
& Proposed model & 12 & 61 & $80.3 \%$ \\
& Secondary results of & 0 & 61 & $100 \%$ \\
\hline
\end{tabular}

measures, group capability index (GCI), which has been proposed by Hsu [29], is used here. The reason for selecting the GCI as the performance measure in this study is due to its simultaneous consideration of production volume and processing time of operations. GCI excludes voids ("zero" entries) from the calculation of goodness, and it can be formulated as follow:

$$
\mathrm{GCI}=1-\frac{e_{0}}{e},
$$

where $e_{0}$ is the number of exceptional elements in the machine part matrix and $e$ is the total number of "one" entries in the machine component matrix.

The results of the first example from Table 6 are compared with the results of rank order clustering (ROC) model [30], by means of GCI performance measure. Similarly, the results of second example (Tables 9 and 10) are compared with the results of ROC2 and Hamiltonian Path Heuristics (HPH) models [6], by means of GCI performance measure. These comparisons are presented in Table 11. For the sake of concise presentation, those steps required to solve the examples with above-mentioned models are not described in this paper. From Table 10 it can be observed that the proposed model represents improvements in GCI, in comparison with the other models. Furthermore, the proposed model of this study considers practical features such as operation sequence and machine capacity, while the ROC, ROC2, and HPH models are not able to take these features into consideration.

\section{Conclusions}

In this paper a mathematical model was developed in order to solve the cell formation (CF) problem in the cellular manufacturing (CM) systems. This mathematical model takes into account the features such as production volume of each part, operations sequence of each part, intercell traffic movement cost with focusing on different travel distance between cells, machine capacity, and machine replication. The model designs cells with the flexibility of choosing the number of cells and specifying limits on the number of machines per cell. The model also formulated in a way so as to ensure a unidirectional flow of material between cells. This feature results in eliminating the intercell backtracking, which simplifies the material handling. In order to examine the proposed model, two numerical examples with different specifications from existing literature were considered. The examples were solved by means of LINGO optimization software. In order to evaluate the performance of the proposed model, it was compared with some existing well-known models, including rank order clustering (ROC), ROC2, and Hamilton path heuristic ( $\mathrm{HPH})$, by means of group capability index (GCI) performance measure. In conclusion, we can say that the proposed CF model in this paper has a high and acceptable performance, and it is reliable for the design and analysis of the cellular manufacturing (CM) systems.

\section{Conflict of Interests}

The authors certify that there is no conflict of interests (considering both financial and nonfinancial gains) with any organization regarding the material discussed in the paper.

\section{References}

[1] H. M. Selim, R. G. Askin, and A. J. Vakharia, "Cell formation in group technology: review, evaluation and directions for future research," Computers and Industrial Engineering, vol. 34, no. 1, pp. 3-20, 1998.

[2] G. Papaioannou and J. M. Wilson, "The evolution of cell formation problem methodologies based on recent studies (19972008): review and directions for future research," European Journal of Operational Research, vol. 206, no. 3, pp. 509-521, 2010.

[3] A. Mungwattana, Design of Cellular Manufacturing Systems for Dynamic and Uncertain Production Requirements with Presence of Routing Flexibility, Virginia Polytechnic Institute and State University, Blacksburg, Va, USA, 2000.

[4] U. Wemmerlöv and N. L. Hyer, "Procedures for the part family/machine group identification problem in cellular manufacturing," Journal of Operations Management, vol. 6, no. 2, pp. 125-147, 1986.

[5] J. C. Wei and N. Gaither, "A capacity constrained multiobjective cell formation method," Journal of Manufacturing Systems, vol. 9, no. 3, pp. 222-232, 1990.

[6] R. G. Askin, S. H. Cresswell, J. B. Goldberg, and A. J. Vakharia, "Hamiltonian path approach to reordering the part-machine matrix for cellular manufacturing," International Journal of Production Research, vol. 29, no. 6, pp. 1081-1100, 1991.

[7] S. J. Chen and C. S. Cheng, "A neural network-based cell formation algorithm in cellular manufacturing," International Journal of Production Research, vol. 33, no. 2, pp. 293-318, 1995.

[8] H. M. Chan and D. A. Milner, "Direct clustering algorithm for group formation in cellular manufacture," Journal of Manufacturing Systems, vol. 1, no. 1, pp. 65-75, 1982.

[9] S. Zolfaghari, "Design and plannng for cellular manufacturing: application of neural networks and advanced search 
techniques," in Mechanical Engineering, Universty of Ottawa, Ottawa, Canada, 1997.

[10] R. Logendran, "A biary integer programming approach for simultaneous machine-part grouping in cellular manufacturing systems," Computers and Industrial Engineering, vol. 24, no. 3, pp. 329-336, 1993.

[11] S. Zolfaghari and M. Liang, "Comprehensive machine cell/part family formation using genetic algorithms," Journal of Manufacturing Technology Management, vol. 15, no. 6, pp. 433-444, 2004.

[12] R. Raminfar, N. Zulkifli, M. R. Vasili, and T. Sai Hong, "An integrated model for production planning and cell formation in cellular manufacturing systems," Journal of Applied Mathematics, vol. 2013, Article ID 487694, 10 pages, 2013.

[13] F. M. Defersha and M. Chen, "A comprehensive mathematical model for the design of cellular manufacturing systems," International Journal of Production Economics, vol. 103, no. 2, pp. 767-783, 2006.

[14] N. Singh, "Design of cellular manufacturing systems: an invited review," European Journal of Operational Research, vol. 69, no. 3, pp. 284-291, 1993.

[15] H. Seifoddini, "Duplication process in machine cells formation in group technology," IIE Transactions, vol. 21, no. 4, pp. 382388, 1989.

[16] S. Viswanathan, "A new approach for solving the $P$-median problem in group technology," International Journal of Production Research, vol. 34, no. 10, pp. 2691-2700, 1996.

[17] G. K. Adil, D. Rajamani, and D. Strong, "Cell formation considering alternate routeings," International Journal of Production Research, vol. 34, no. 5, pp. 1361-1380, 1996.

[18] S. Sofianopoulou, "Manufacturing cells design with alternative process plans and/or replicate machines," International Journal of Production Research, vol. 37, no. 3, pp. 707-720, 1999.

[19] N. Safaei and R. Tavakkoli-Moghaddam, "Integrated multiperiod cell formation and subcontracting production planning in dynamic cellular manufacturing systems," International Journal of Production Economics, vol. 120, no. 2, pp. 301-314, 2009.

[20] N. E. Dahel, "Design of cellular manufacturing systems in tandem configuration," International Journal of Production Research, vol. 33, no. 8, pp. 2079-2095, 1995.

[21] J. R. King and V. Nakornchai, "Machine-component group formation in group technology: review and extension," International Journal of Production Research, vol. 20, no. 2, pp. 117-133, 1982.

[22] R. Logendran, P. Ramakrishna, and C. Sriskandarajah, “Tabu search-based heuristics for cellular manufacturing systems in the presence of alternative process plans," International Journal of Production Research, vol. 32, no. 2, pp. 273-297, 1994.

[23] A. Atmani, R. S. Lashkari, and R. J. Caron, "A mathematical programming approach to joint cell formation and operation allocation in cellular manufacturing," International Journal of Production, vol. 33, no. 1, pp. 1-15, 1995.

[24] M. Chen, "A model for integrated production planning in cellular manufacturing systems," Integrated Manufacturing Systems, vol. 12, no. 4, pp. 275-284, 2001.

[25] LINDO Systems, LINGO User's Guide, LINDO System, Chicago, Ill, USA, 2010.

[26] M. P. Chandrasekharan and R. Rajagopalan, "An ideal seed nonhierarchical clustering algorithm for cellular manufacturing," International Journal of Production Research, vol. 24, no. 2, pp. 451-463, 1986.
[27] F. M. Defersha and M. Chen, "A parallel multiple Markov chain simulated annealing for multi-period manufacturing cell formation problems," International Journal of Advanced Manufacturing Technology, vol. 37, no. 1-2, pp. 140-156, 2008.

[28] B. R. Sarker, "Grouping efficiency measures in cellular manufacturing: a survey and critical review," International Journal of Production Research, vol. 37, no. 2, pp. 285-314, 1999.

[29] C. P. Hsu, The Similarity Coefficient Approaches of MachineComponent Cell Formation in Cellular Manufacturing: A Comparative Study, University of Wisconsin-Milwaukee, Milwaukee, Wis, USA, 1990.

[30] M. P. Groover, Automation, Production Systems, and ComputerIntegrated Manufacturing, Prentice Hall Press, 2007. 


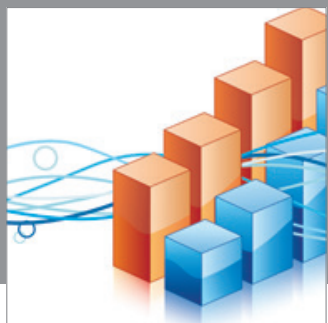

Advances in

Operations Research

mansans

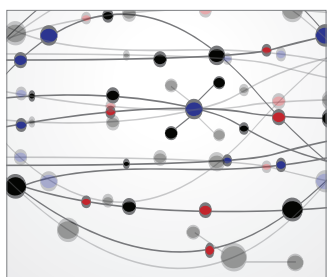

The Scientific World Journal
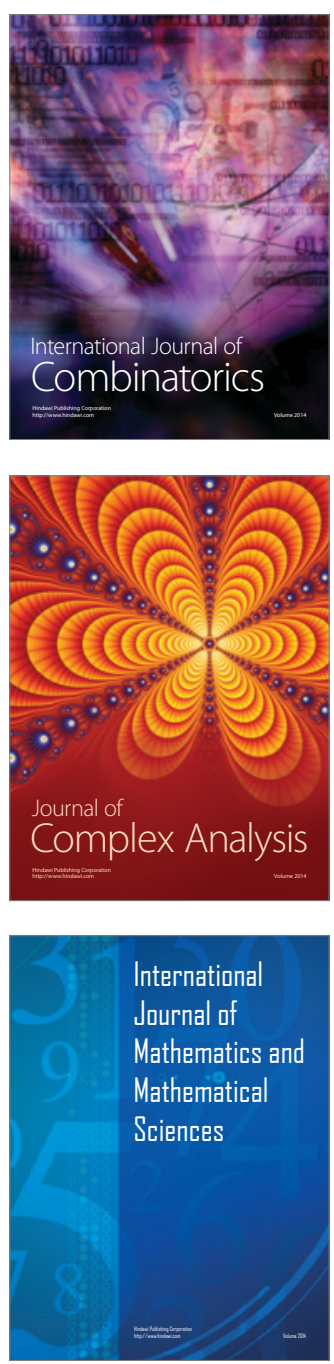
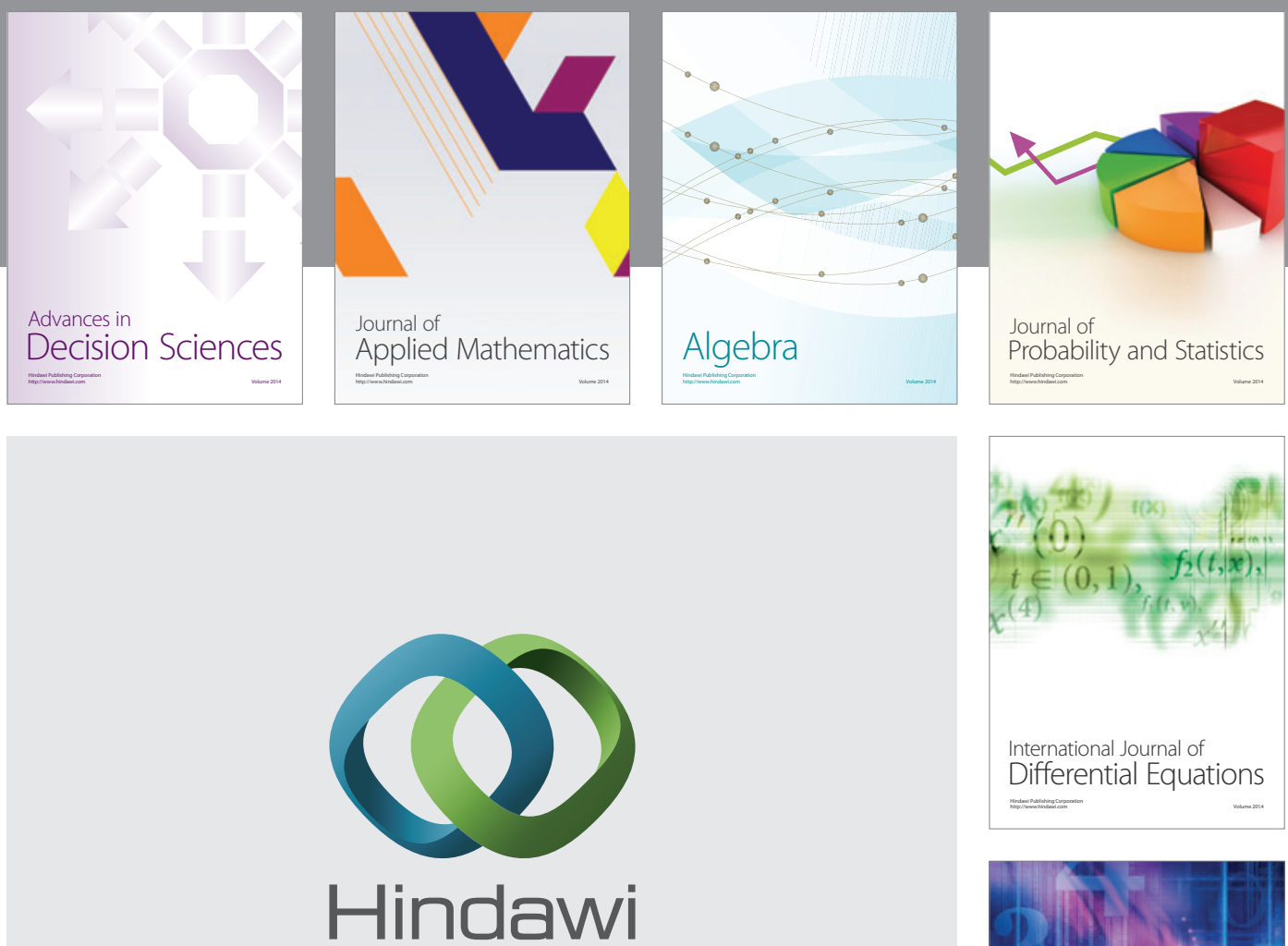

Submit your manuscripts at http://www.hindawi.com
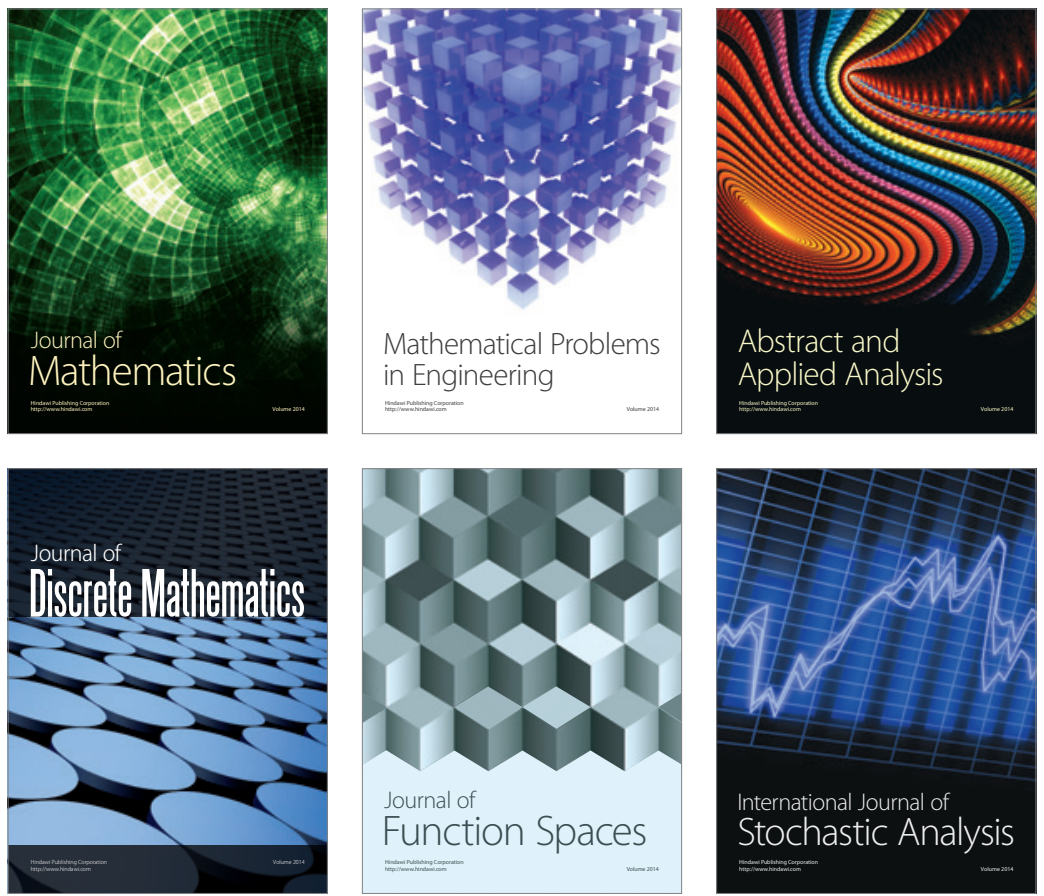

Journal of

Function Spaces

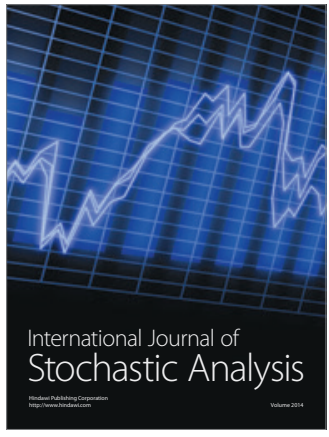

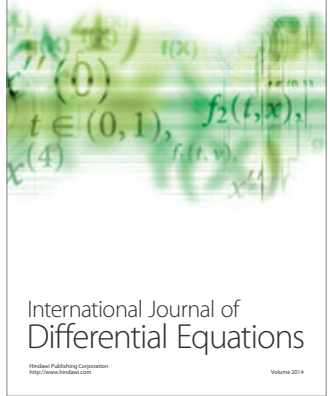
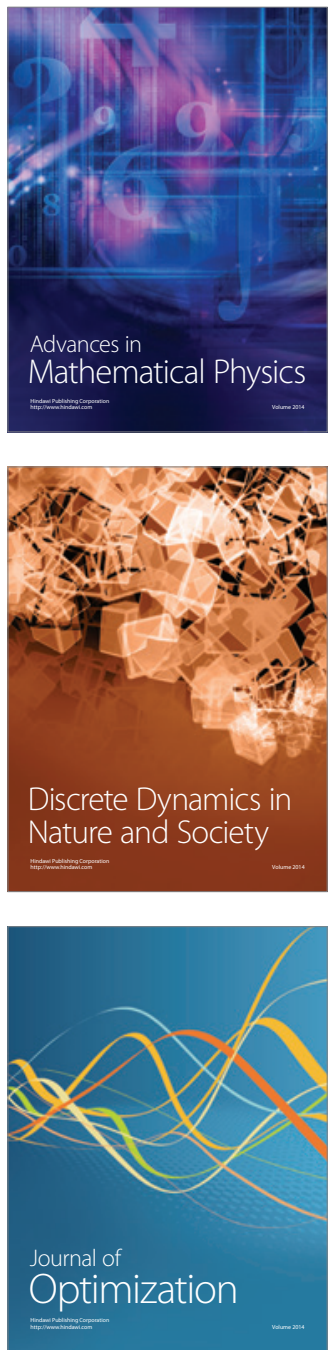